\title{
Winning images from the Photography in Medical Physics (PiMP) competition
}

๑) Australasian College of Physical Scientists and Engineers in Medicine 2021

“Don't Drop the Ball!”, (C) Georgia Friend

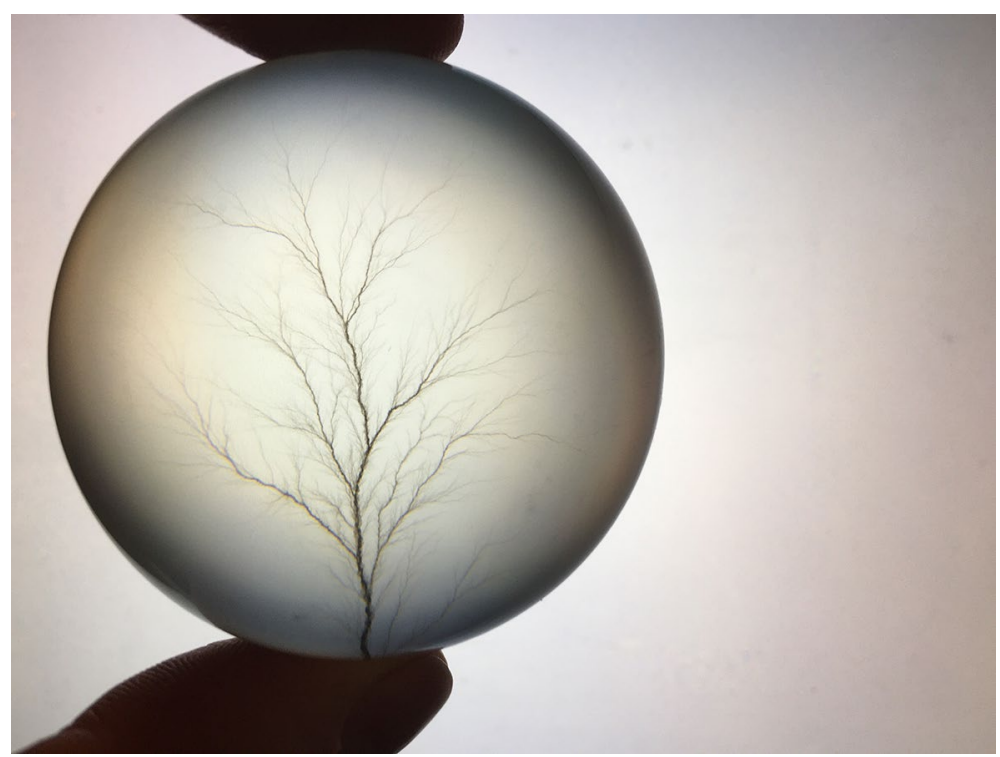

Winning images from the Photography in Medical Physics (PiMP) competition http://photographyinmedicalphysi cs.com/ https://www.facebook.com/go4PIMP/

Joerg Lehmann (University of Sydney); May Whitaker (Chris O'Brien Lifehouse); and Alannah Kejda (Blacktown Hospital); Hans from Gamma Gurus.
Winners are judged by a jury of professionals from Medical Physics and Photography, and also by People's choice (members of the ACPSEM).

Publisher's Note Springer Nature remains neutral with regard to jurisdictional claims in published maps and institutional affiliations. 